\title{
$N$-Linked Protein Glycosylation in the Endoplasmic Reticulum
}

\author{
Jörg Breitling and Markus Aebi \\ Institute of Microbiology, Department of Biology, ETH Zurich, CH-8093 Zurich, Switzerland \\ Correspondence: markus.aebi@micro.biol.ethz.ch
}

The attachment of glycans to asparagine residues of proteins is an abundant and highly conserved essential modification in eukaryotes. The $\mathrm{N}$-glycosylation process includes two principal phases: the assembly of a lipid-linked oligosaccharide (LLO) and the transfer of the oligosaccharide to selected asparagine residues of polypeptide chains. Biosynthesis of the LLO takes place at both sides of the endoplasmic reticulum (ER) membrane and it involves a series of specific glycosyltransferases that catalyze the assembly of the branched oligosaccharide in a highly defined way. Oligosaccharyltransferase (OST) selects the Asn-X-Ser/Thr consensus sequence on polypeptide chains and generates the $\mathrm{N}$-glycosidic linkage between the side-chain amide of asparagine and the oligosaccharide. This ER-localized pathway results in a systemic modification of the proteome, the basis for the Golgi-catalyzed modification of the $\mathrm{N}$-linked glycans, generating the large diversity of $\mathrm{N}$-glycoproteome in eukaryotic cells. This article focuses on the processes in the ER. Based on the highly conserved nature of this pathway we concentrate on the mechanisms in the eukaryotic model organism Saccharomyces cerevisiae.

$\mathrm{T}_{\mathrm{t}}^{\mathrm{h}}$ he presence of glycans on proteins is known to influence their stability and solubility and the glycan core can contribute to folding processes (Shental-Bechor and Levy 2008; Hanson et al. 2009; Culyba et al. 2011). N-glycans also influence the function and activity of proteins (Skropeta 2009). The terminal residues of $N$ glycans play a key role in the quality control of protein folding in the ER. Ultimately the glycan signals whether a protein is correctly folded and can leave the ER to continue its maturation in the Golgi or whether the protein is not correctly folded and is degraded (Helenius and Aebi 2004; Aebi et al. 2010). It is therefore of great importance that the oligosaccharide to be transferred to proteins is complete. This "quality control" of the oligosaccharide is mediated by the substrate specificity of oligosaccharyltransferase.

\section{BIOSYNTHESIS OF THE LIPID-LINKED OLIGOSACCHARIDE}

Dolichol, the Lipid Carrier in ER Glycosylation

The biosynthesis of the lipid-linked oligosaccharides (LLO) takes place at the membrane of the ER and is characterized by the involvement of a special lipid as a carrier, dolichol, as well as the bipartite localization of the pathway in the cytoplasm and the lumen of the ER. Dolichol

Editors: Susan Ferro-Novick, Tom A. Rapoport, and Randy Schekman

Additional Perspectives on The Endoplasmic Reticulum available at www.cshperspectives.org

Copyright (C) 2013 Cold Spring Harbor Laboratory Press; all rights reserved; doi: 10.1101/cshperspect.a013359

Cite this article as Cold Spring Harb Perspect Biol 2013;5:a013359 
J. Breitling and M. Aebi

belongs to a group of polyisoprenoid molecules with a saturated $\alpha$-isoprene unit. It is synthesized by the cis-prenyl transferase that elongates farnesyl pyrophosphate by the sequential addition of activated isopentenyl pyrophosphate units. The chain length of dolichol varies in different organisms. It mainly consists of 15-16 isoprene units in S. cerevisiae (Jung and Tanner 1973; Adair and Cafmeyer 1987), whereas 18-21 isoprene units are found in dolichol from mammalian cells (Rip et al. 1985) and shorter dolichols with 11-12 isoprene units were described in the protozoan parasite Trypanosoma brucei (Low et al. 1991). The mechanism by which dolichol chain length is regulated is not completely understood, although regions and amino acid residues of bacterial cis-prenyltransferases were identified that seem to regulate the final length of the polyprenyl-pyrophosphate product (Chen et al. 2005; Kharel et al. 2006). Models for the final steps of the dolichol biosynthesis suggest that the polyprenyl-pyrophosphate product is first dephosphorylated (Schenk et al. 2001) before the $\alpha$-isoprene unit is reduced by a nicotinamide adenine dinucleotide phosphate (NADPH)-dependent $\alpha$-reductase (Sagami et al. 1993; Szkopinska et al. 1996; Cantagrel et al. 2010). The $\alpha$-saturated isoprene is then phosphorylated to form dolichyl phosphate (Dol-P). In yeast, SEC59 encodes the CTP-dependent dolichol kinase and complementation of the yeast sec59-1 conditional mutant with cDNA allowed the identification of the human homolog of SEC59, hDK1 (Heller et al. 1992; Fernandez et al. 2002).

\section{Biosynthesis of the LLO Building Blocks}

The LLO consists of three principal carbohydrate components. It contains two $N$-acetylglucosamine (GlcNAc), nine mannose (Man), and three glucose (Glc) residues (Fig. 1). These sugar residues are added to the LLO either from soluble, nucleotide-activated sugar donors, or from Dol-P-linked sugars. The former group of glycosyltransferases acts in the cytoplasm, and the latter in the lumen of the ER.

The biosynthesis of UDP-Glc uses Glc-6phosphate as a precursor, which is first con-

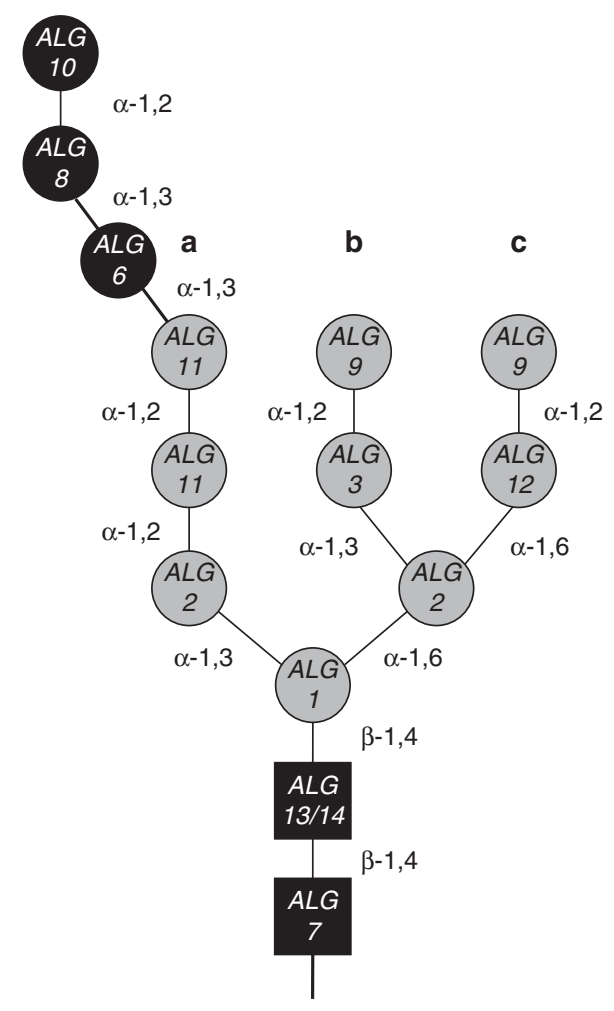

Figure 1. Structure of the $N$-glycan. The $N$-glycan structure consists of 14 carbohydrate residues. It contains two $\mathrm{N}$-acetylglucosamines (GlcNAc, black squares), nine mannoses (Man, gray circles), and three glucoses (Glc, black circles). Linkage information is indicated between carbohydrate residues. The different residues are labeled with the genes encoding the glycosyltransferase that catalyzes the transfer of the respective residue. The structure of the glycan has three branches labeled a, b, and c.

verted to Glc-1-phosphate before UDP-Glc is formed (Boles et al. 1994; Daran et al. 1995). The biosynthesis of GDP-Man and UDPGlcNAc uses fructose-6-phosphate as a precursor, which is generated from Glc-6-phosphate by enzymatic isomerization (Dickinson 1991). UDP-GlcNAc is then synthesized in four steps from fructose-6-phosphate (Milewski et al. 2006). For the biosynthesis of GDP-Man, fructose-6-phosphate is isomerized to mannose-6phosphate, which is converted to mannose-1phosphate before GDP-Man is synthesized (Kepes and Schekman 1988; Smith et al. 1992; Hashimoto et al. 1997). 
Dol-P-bound sugars serve as substrates for glycosyltransferases involved in the ER lumenal phase of LLO biosynthesis. Dol-P-Man and Dol-P-Glc are synthesized from Dol-P, GDPMan, and UDP-Glc, respectively, at the cytosolic face of the ER membrane (Fig. 2). Both reactions lead to an inversion from $\alpha$ to $\beta$ at the anomeric center. Dol-P-Man is generated by the Dol-P-Man synthase. Although in yeast DPM1 encodes Dol-P-Man synthase (Orlean et al. 1988), the mammalian enzyme is a complex of three proteins, in which the homolog of Dpmlp is the catalytic subunit (Maeda et al. 1998; Maeda et al. 2000). Dol-P-Man is not only required for LLO biosynthesis but is also needed for O-mannosylation, glycosyl phosphatidylinositol (GPI) anchor biosynthesis, and $C$-mannosylation, a rare protein modification of tryptophan side chains (Orlean 1990; Doucey et al. 1998). Dol-P-Glc is generated by the ALG5-encoded synthase, which transfers glucose-phosphate from the UDP-Glc donor (te Heesen et al. 1994). Although DPM1 is essential in yeast, a deletion of ALG5 has no effect on growth, but results in hypoglycosylation of $N$-glycoproteins (Orlean et al. 1988; te Heesen et al. 1994). Both Dol-P-Glc and Dol-P-Man need to be translocated from the cytosolic leaflet, where they are synthesized, to the lumenal face of the ER membrane. For Dol-P-Man and

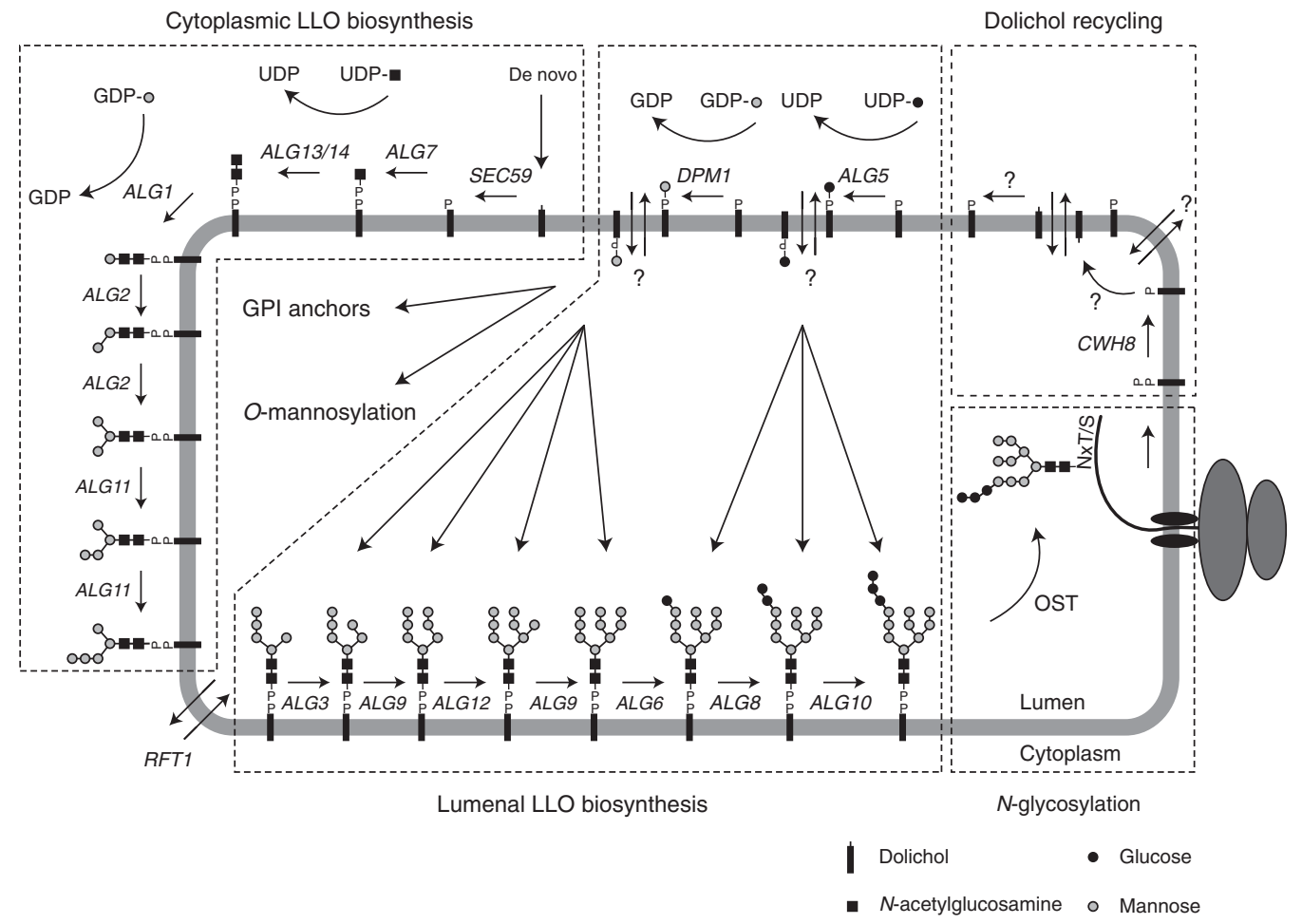

Figure 2. The asparagine-linked glycosylation pathway. The biosynthesis of lipid-linked oligosaccharide (LLO) is catalyzed by a series of glycosyltransferases encoded by asparagine-linked glycosylation $(A L G)$ genes. The buildup of the glycan is initiated at the cytoplasmic leaflet of the ER membrane by the addition of $N$-acetylglucosamine (GlcNAc)-phosphate to dolichol-phosphate (Dol-P) from nucleotide-activated UDP-GlcNAc. After the addition of a second GlcNAc residue to Dol-PP-GlcNAc, five mannoses (Man) are attached from GDP-Man to the LLO. After translocation into the ER lumen, four additional Man from Dol-P-Man and three glucoses are added from Dol-P-Glc. The oligosaccharide is then transferred en bloc to asparagine side chains of nascent polypeptides by the oligosaccharyltransferase (OST). The synthesis of dolichol and dolichol-bound monosaccharide precursors as well as proposed models for dolichol recycling are discussed in detail in the text. 
Dol-P-Glc analogues, a specific protein-assisted translocation was shown in vitro (Rush and Waechter 1995; Rush et al. 1998; Rush and Waechter 2004) and Dol-P-Man translocation activity was shown to be ATP independent (Sanyal and Menon 2010). However, the proteins responsible for Dol-P-Man as well as for Dol-P-Glc translocation across the ER membrane have not been identified so far and no yeast mutant strain with appropriate phenotypes has been characterized.

Initial Steps of LLO Biosynthesis on the Cytoplasmic Side of the ER Membrane

The buildup of the oligosaccharide on a lipid linker increases the local concentration of the LLO intermediates for the enzymes involved in the biosynthesis process as well as for oligosaccharyltransferase (OST) that transfers the glycan to substrate proteins. All these enzymes are membrane bound or membrane associated and a membrane-bound substrate increases the flux through the pathway. In addition, some of the biosynthetic enzymes are organized in complexes to further optimize the multireaction processes.

LLO biosynthesis is executed by a series of glycosyltransferases encoded by the asparagine-linked glycosylation $(A L G)$ pathway genes (Fig. 2). The buildup of the LLO is initiated at the cytoplasmic face of the ER membrane where the $N$-acetylglucosamine-phosphate transferase encoded by ALG7 uses UDP-GlcNAc to add GlcNAc-P to the Dol-P lipid carrier to form the anhydride dolichyl-pyrophosphate-GlcNAc (Dol-PP-GlcNAc). This enzyme is essential in yeast and can be inhibited by tunicamycin, a drug often used to study the effects of blocked $N$-glycosylation on cellular processes (Rine et al. 1983; Elbein 1984; Kukuruzinska and Robbins 1987). The second GlcNAc residue is added to Dol-PP-GlcNAc by a protein complex encoded by $A L G 13$ and $A L G 14$ (Bickel et al. 2005). It was proposed that Alg7p, Alg13p, and Alg14p form a complex that utilizes UDP-GlcNAc as the common substrate and facilitates efficient glycosylation by passing on LLO intermediates to consecutive active sites without diffusion (Noffz et al.
2009). Investigations on this complex formation indicated that Alg14p serves as the central organizing subunit that interacts with Alg13p and, in addition, recruits Alg7p into the complex ( $\mathrm{Lu}$ et al. 2012).

The subsequent steps of LLO biosynthesis on the cytosolic leaflet transfer Man residues and use GDP-Man as the donor substrate. The first Man is added to Dol-PP-GlcNAc ${ }_{2}$ by the ALG1encoded $\beta-1,4$ mannosyltransferase (Couto et al. 1984). The addition of the two branching Man residues is performed by Alg2p to generate Dol-PP-GlcNAc ${ }_{2} \mathrm{Man}_{3}$ (Fig. 1). This enzyme adds first the $\alpha-1,3$ - and subsequently the $\alpha$ 1,6-linked Man (O'Reilly et al. 2006; Kampf et al. 2009). The mechanism for how Alg2p can conduct two different mannosylation reactions is not understood so far. The lipid-linked $\mathrm{GlcNAc}_{2} \mathrm{Man}_{3}$ pentasaccharide serves as substrate for Alg11p that elongates the LLO by two $\alpha$-1,2-linked Man residues (Cipollo et al. 2001; O'Reilly et al. 2006). Interestingly, the three cytoplasm-oriented mannosyltransferases also form a hetero-oligomeric complex (Gao et al. 2004). This results in two biosynthetic platforms that are characterized by the nucleotide-activated sugar substrate: the UDP-GlcNAc utilizing Alg7p/Alg13p/Alg14p and the GDP-Man-dependent Alg1p/Alg2p/Alg11p complex.

Dol-PP-GlcNAc ${ }_{2} \mathrm{Man}_{5}$ is the final product of the $A L G$ pathway on the cytosolic leaflet of the ER membrane (Fig. 2). To be further elongated the LLO needs to be translocated into the ER lumen, a process that is protein mediated (McCloskey and Troy 1980; Snider and Rogers 1984; Rush and Waechter 1995; Rush et al. 1998). Genetic studies indicated that Rftlp is required for the transbilayer movement of the LLO. This conclusion was based on the phenotype of an $r f t 1$ mutant strain: complete prevention of $N$-linked protein glycosylation and accumulation of the lipid-linked GlcNAc ${ }_{2} \mathrm{Man}_{5}$ oligosaccharide (Helenius et al. 2002). However, in vitro translocation assays found Rftlp-independent LLO flipping (Frank et al. 2008; Sanyal et al. 2008; Rush et al. 2009). The contradicting results of in vivo and in vitro studies question the function of Rft1p and therefore call for further investigations to unambiguously identify 
the flippase. In vitro, flippase activity was shown to be substrate specific because preferential translocation of the physiological substrate (Dol-PP-GlcNAc $2 \mathrm{Man}_{5}$ ) compared with other LLO forms was observed (Sanyal et al. 2008; Sanyal and Menon 2009).

\section{LLO Biosynthesis: ER Lumenal Phase}

After translocation of Dol-PP-GlcNAc ${ }_{2} \mathrm{Man}_{5}$ into the ER lumen, four additional mannosyl residues are attached to the LLO before capping by three terminal glucoses completes LLO biosynthesis (Figs. 1 and 2). Unlike the glycosyltransferases acting on the cytosolic leaflet, the lumenal enzymes elongate the LLO by using Dol-P-bound sugar substrates (i.e., Dol-P-Glc and Dol-P-Man). All lumenally acting ALG enzymes are grouped in the GT-C superfamily of glycosyltransferases. Based on their primary sequence the enzymes adopt similar folds and all use lipid-bound phosphate-activated sugars as donor substrates. They are inverting enzymes, resulting in an $\alpha$ configuration of the transferred glycan unit (Lairson et al. 2008).

ALG3 encodes the $\alpha-1,3$ mannosyltransferase that initiates the b branch of the LLO (Fig. 1) (Aebi et al. 1996; Sharma et al. 2001). The subsequent addition of an $\alpha$-1,2-linked Man is catalyzed by the ALG9-encoded mannosyltransferase (Cipollo and Trimble 2000; Frank and Aebi 2005). After the b branch is completed by Alg9p, the first $\mathrm{c}$ branch Man is added by Alg12p in $\alpha-1,6$ linkage (Burda et al. 1999; Cipollo and Trimble 2002). The c branch is also capped by an $\alpha$-1,2-linked Man residue added by Alg9p (Fig. 1). Alg9p therefore has a dual function in LLO biosynthesis by adding two $\alpha$-1,2-linked Man residues that cap the $b$ and the $c$ branch (Frank and Aebi 2005).

The mature LLO structure carries three Glc residues at the nonreducing $\alpha-1,2$ Man of the a branch (Fig. 1). The first Glc is added in $\alpha-1,3$ linkage by the ALG6-encoded glucosyltransferase. Deletion of the ALG6 gene therefore leads to the same unglucosylated LLO structure as is observed in yeast cells that fail to synthesize Dol-PGlc owing to ALG5 deletion (Reiss et al. 1996). Alg8p subsequently adds the second $\alpha-1,3-$ linked Glc residue to the LLO (Stagljar et al. 1994). The final step in LLO synthesis, which is catalyzed by Alg10p, attaches a third Glc residue in $\alpha-1,2$ linkage (Burda and Aebi 1998).

The assembly of the LLO in the lumen of the ER is remarkably ordered. This is owing to high substrate specificities of the involved $A L G$ enzymes toward their respective substrates. This ordered assembly of the branched structures ensures the complete assembly of the LLO. For example, Alg12p only initiates the $c$ branch when Alg9p has completed the b branch (Burda et al. 1999). Similarly, glucosylation of the a branch is favored by the presence of the complete $b$ and $c$ branches (Burda et al. 1999). Alg6p therefore functions as a gatekeeper to ensure that mannosylation of the LLO is completed before the final glucosylation steps are initiated. Completion of the LLO is signaled by the addition of the $\alpha-1,2$-linked Glc, catalyzed by Alg10p (Burda and Aebi 1998). The ordered assembly of the branched oligosaccharide has several consequences. (1) In conjunction with the high degree of conservation of the pathway among eukaryotes, the mature LLO structures of yet uncharacterized organisms can be predicted based on their ALG genes (Samuelson et al. 2005). (2) Mutations and deletions affecting the lumen-oriented $A L G$ glycosyltransferases result in the accumulation of the corresponding LLO intermediate. (3) Owing to the high substrate specificity of OST that requires a terminal $\alpha$-1,2-linked Glc for efficient transfer to proteins, such mutations result in a hypoglycosylation of the $\mathrm{N}$-glycoproteome. (4) Biosynthetic intermediates differ from processed $N$-linked glycans. For instance, the removal of the $\alpha$-1,2-linked Man of the b branch by ERmannosidase I yields a protein-specific glycan structure that is not present as a biosynthetic intermediate in LLO biosynthesis.

\section{The Dolichol Cycle}

The availability of Dol-P at the cytosolic side of the ER membrane is crucial for the process of $\mathrm{N}$-glycosylation and it might become a ratelimiting factor in the biosynthesis of LLO (Burda and Aebi 1999; Schenk et al. 2001). 
Dol-P can be generated de novo by the biosynthetic pathway described above, but is also a product of glycosyltransferases using Dol-PMan and Dol-P-Glc as substrate in the ER lumen. In addition, Dol-P can be generated by dephosphorylation of Dol-PP, which is liberated as a product of the OST-catalyzed $N$-glycosylation reaction. Hence, $N$-linked protein glycosylation results in a transfer of Dol-P from the cytosolic to the lumenal side of the ER membrane. Current models suggest that Dol-P liberated in the ER lumen is recycled. These models are based on the observation that yeast cells that lack the CWH8 Dol-PP phosphatase (DolPP1 in mammals [Rush et al. 2002]) are impaired in $N$-glycosylation and LLO biosynthesis (van Berkel et al. 1999; Fernandez et al. 2001).

Dol-PP liberation by OST activity rapidly increases Dol-P levels on the cytosolic side of the membrane (Rush et al. 2008). Because the phosphoryl group of Dol-P prohibits free diffusion across the membrane (McCloskey and Troy 1980), the rapid availability of Dol-P on the cytosolic leaflet suggests flippase-assisted translocation across the membrane, which could be facilitated by a hypothetical Dol-P-Man flippase (Sanyal and Menon 2010). Alternatively, Dol-P could be further dephosphorylated to Dol in the ER lumen, which could then traverse the membrane freely to get rephosphorylated by the dolichol kinase on the cytoplasmic face of the membrane (Fig. 2). Experiments suggest, however, that Dol kinase is not involved in Dol recycling (Rush et al. 2008).

Although Dol-P is released by various glycosylation reactions in the ER lumen (i.e., LLO biosynthesis, $\mathrm{C}$ - and $\mathrm{O}$-mannosylation, and GPI anchor biosynthesis), it is not clear why a lack of Dol-PP phosphatase activity results in a hypoglycosylation and growth phenotype in yeast. The $\Delta c w h 8$ mutation might affect translocation of Dol-P through the ER membrane to the cytosolic face. In addition, or alternatively, most of the cellular Dol-P might accumulate as DolPP over continuous rounds of LLO biosynthesis (i.e., on Dol-PP) and subsequent liberation of Dol-PP by the OST-catalyzed $N$-glycosylation reaction. If de novo synthesis does not compensate for the "trapped" Dol-PP, Dol-P levels could become limiting (Fernandez et al. 2001; Rush et al. 2008). Further work will be necessary to clarify whether, and by what mechanism, Dol$\mathrm{PP}$ accumulation causes the reduction in Dol-P levels.

\section{THE OLIGOSACCHARYLTRANSFERASE}

\section{Complex versus Single Protein \\ Oligosaccharyltransferase}

The OST is the central enzyme in $N$-linked glycosylation. It transfers the glycan from the LLO substrate en bloc to asparagine side chains of polypeptides. In animals, plants, and fungi the OST is a hetero-oligomeric complex. The subunits of the yeast OST complex are encoded by OST3, OST4, OST5, and OST6, and the essential genes OST1, OST2, WBP1, SWP1, and STT3 (Kelleher and Gilmore 2006). The yeast OST complex exists in two isoforms that differ with respect to either Ost6p or Ost3p (Schwarz et al. 2005; Spirig et al. 2005; Yan and Lennarz 2005). In mammalian OST complexes, subunits homologous to yeast proteins (in parentheses) are found: DAD1 (Ost2p), N33/Tusc3 and IAP3 (Ost3p and Ost6p), OST48 (Wbplp), ribophorin I (Ost1p), ribophorin II (Swp1p), and STT3A and STT3B (Stt3p) (Mohorko et al. 2011). Isoforms of the complex containing either STT3A or STT3B were described (Kelleher et al. 2003). The newly identified subunits KCP2 and DC2 seem to associate with mammalian OST complexes (Shibatani et al. 2005; Wilson et al. 2011; Roboti and High 2012a).

OST complexes of unicellular eukaryotes only possess some of the OST subunits found in S. cerevisiae. Although Cryptosporidium parvum encodes most of the OST subunits found in yeast, except for OST5 and SWP1, more simple OST complexes are present in Trichomonas vaginalis, Entamoeba histolytica, and Plasmodium falciparum genomes (Kelleher and Gilmore 2006). Here, homologs of Ost1p, Ost2p, Stt3p, and Wbplp were identified. Giardia lamblia and kinetoplastids encode only STT3 homologs (Kelleher and Gilmore 2006). Interestingly, some kinetoplastids encode several paralogs of STT3 that have been shown to function as 
single subunit OSTs (Parsaie Nasab et al. 2008; Hese et al. 2009; Izquierdo et al. 2009).

The addition of supplementary, modulating subunits to the catalytically active STT3 protein is thought to enable organisms to glycosylate a more diverse range of substrate proteins. Duplication and diversification of single subunit OSTs seems to represent an alternative strategy to enlarge the array of proteins accessible for glycosylation (Schwarz and Aebi 2011). For instance, T. brucei and Leishmania major encode STT3 paralogs with distinct preferences for their polypeptide substrate (Parsaie Nasab et al. 2008; Izquierdo et al. 2009).

OST encounters two distinct substrates: the LLO and nascent polypeptide chains. The nature of the substrates requires two different types of enzyme-substrate interaction. The LLO substrate structure is conserved but biosynthetic intermediates are located at the same site at the ER membrane. Thus, OST must interact with the donor substrate in a highly specific way that favors the transfer of the mature LLO structure. Conversely, polypeptide substrates only seem to share the conserved $\mathrm{NxT} / \mathrm{S}$ sequon, allowing a great diversity for the rest of the polypeptide. Hence, OST needs to perform a wide spectrum of interactions to successfully glycosylate the multitude of polypeptide substrates.

\section{The LLO Donor Substrate}

The donor substrate of OSTs is a LLO with 14 glycan residues. Hence, the question arises whether all these residues are important for the transfer reaction catalyzed by the OST. In vitro studies were used to establish that the minimal LLO structure transferred by OST is Dol-PP-GlcNAc 2 (Tai and Imperiali 2001). DolPP-GlcNAc $\mathrm{Man}_{3}$ seems to be the minimal LLO structure that allows yeast cells to grow, as long as the limiting translocation across the ER membrane is bypassed by $\mathrm{Rft} 1 \mathrm{p}$ overexpression ( $\mathrm{He}$ lenius et al. 2002).

Deletions of $A L G$ genes encoding ER lumenal enzymes do not display growth phenotypes in yeast but result in protein hypoglycosylation. The defect in glycosylation becomes less severe when $b$ branch mannoses get added to the LLO $(\Delta a \lg 3>\Delta$ alg $9>\Delta$ alg12) owing to glucosylation of the intermediates that is more efficient when the b branch is completed (Verostek et al. 1993; Burda et al. 1999; Cipollo and Trimble 2000). Overexpression of the rate-limiting first glucosyltransferase Alg6p therefore improves protein glycosylation in the $\Delta a \lg 9, \Delta a \lg 12$, and even in the $\Delta$ alg3 strain (Burda and Aebi 1998; Burda et al. 1999). In fact, LLO glucosylation has been a long known key determinant for efficient transfer of the oligosaccharide to proteins by the OST complex in vivo and in vitro (Trimble et al. 1980; Burda and Aebi 1998; Burda et al. 1999; Karaoglu et al. 2001). Especially the terminal $\alpha-1,2$ Glc residue is necessary for efficient glycosylation (Burda and Aebi 1998). In summary, OST seems to recognize the $\mathrm{GlcNAc}_{2}$ core of the LLO and, in addition, the terminal $\alpha-1,2$ Glc residue of the a branch, whereas the Man residues of the $b$ and $c$ branches are of limited importance (Burda et al. 1999).

Apart from the oligosaccharide moiety of the LLO, the lipid carrier also may interact with the OST. In yeast, OST seems to possess certain flexibility toward the length of the LLO dolichol moiety. Biosynthesis of truncated dolichol with $11-12$ isoprene units by a cis-prenyltransferase from G. lamblia in S. cerevisiae did not result in a hypoglycosylation phenotype, indicating that the truncated dolichol is sufficient for the yeast OST to glycosylate proteins (Grabinska et al. 2010). However, yeast OST cannot utilize very short lipid carriers with only three to four isoprene units in vitro (Fang et al. 1995).

\section{Polypeptide Acceptor Substrates}

Although the LLO donor substrate has a highly conserved structure, the acceptor polypeptide substrates are greatly diverse. The most strictly conserved property, the consensus sequon, was found in initial studies of eukaryotic glycoproteins, which established that $N$-glycosylation occurs at asparagine residues located within a sequence motif that consists of asparagine, a second amino acid (any except proline), and threonine or serine (NxT/S) (Marshall 1972). This sequon is also found in prokaryotic 
protein N-glycosylation (Wacker et al. 2002; Abu-Qarn and Eichler 2007). The crystal structure of a bacterial OST shows that the peptide is bound in a loop form that almost completes a $180^{\circ}$ turn. This explains why proline is not allowed at the $\mathrm{x}$ position of the $\mathrm{NxT} / \mathrm{S}$ sequon (Lizak et al.2011). It can be assumed that similar structural constraints also hold true for eukaryotic OSTs, because proline also prohibits glycosylation of eukaryotic sequons. The conservation of the sequon is not absolute because glycosylation of nonconsensus sequons $(\mathrm{NxC}$, $\mathrm{NGx}$, and $\mathrm{NxV}$ ) has been reported in nematodes, plants, and mammals, although these are rare (about $1 \%-2 \%$ ) compared with $\mathrm{NxT} /$ S sequons (Titani et al. 1986; Miletich and Broze 1990; Vance et al. 1997; Sato et al. 2000; Kaji et al. 2003; Zielinska et al. 2010; Matsui et al. 2011). NxT sequons are glycosylated more efficiently than $\mathrm{NxS}$, whereas $\mathrm{NxC}$ sequons are only poorly modified by OST in vitro (Breuer et al. 2001) and in vivo (Gavel and von Heijne 1990; Ben-Dor et al. 2004; Zielinska et al. 2010). Not all sequons are glycosylated in vivo and the overall proportion of glycosylated sequons of database-listed glycoproteins was found to be 61\%-65\% (Ben-Dor et al. 2004; Petrescu et al. 2004). Therefore, additional factors were searched that could prevent glycosylation.

Except for proline, few amino acids in the $\mathrm{x}$ position (Shakin-Eshleman et al. 1996; Kasturi et al. 1997) and in sequences surrounding the sequon were found to influence glycosylation (Ben-Dor et al. 2004; Petrescu et al. 2004). However, proline also has a strong negative effect on glycosylation in the position following NxT/S (Bause 1983; Gavel and von Heijne 1990; BenDor et al. 2004). The position of the sequon within a protein plays a role as well. The distance of the sequon to transmembrane helices (Nilsson and von Heijne 1993) as well as the distance to the carboxyl terminus can influence the glycosylation efficiency, although this effect may be protein specific (Nilsson and von Heijne 2000; Walmsley and Hooper 2003a,b; Bano-Polo et al. 2011).

Increasing proximity of neighboring sequons reduces glycosylation efficiency in vitro, although in vivo an example for glycosylation of two sequons separated by just one amino acid was found (Gavel and von Heijne 1990; Karamyshev et al. 2005). In overlapping sequons (e.g., NNST in yeast invertase), only one asparagine can be glycosylated (Reddy et al. 1988; Reddy et al. 1999).

In summary, several factors in the amino acid sequence can influence the glycosylation of a potential glycosylation site. However, it seems to be most important that NxT/S sequons are located in a flexible or an unfolded domain of the polypeptide.

\section{Cotranslational or Posttranslational Modification?}

Sequons of nascent polypeptide chains located more than 65 amino acid residues away from the $P$ site of the ribosome can get glycosylated when entering the ER lumen. This suggests a largely extended conformation of the nascent polypeptide and a position of the OSTactive site close to the translocon (Whitley et al. 1996; Kowarik et al. 2002). OST complexes of yeast and mammalian cells were suggested to be associated with the translocation complex and to interact with the ribosome (Chavan et al. 2005; Shibatani et al. 2005; Harada et al. 2009). In support of this, antibodies directed against the cytoplasmic domain of ribophorin I prevent protein translocation (Yu et al. 1990). Therefore, cotranslational transfer of $\mathrm{N}$-glycans has been postulated as suggested by experimental data in early years (Chen et al. 1995). Cotranslational modification enables the OST to glycosylate the emerging polypeptide chain before the polypeptide starts to fold. Current models, moreover, suggest that OST can temporarily prevent folding of polypeptides to increase the efficiency of glycosylation (see below).

The two isoforms of the mammalian OST complex, containing either STT3A or STT3B, differ in their catalytic activity and selectivity for the LLO substrate (Kelleher et al. 2003). It is proposed that nascent polypeptide chains can get in contact with several OST isoform complexes, opposed to the model stating that one OST complex associates with one translocon and glycosylates after translocation (Harada et 
al. 2009; Ruiz-Canada et al. 2009). The STT3A OST isoform glycosylates substrate polypeptide chains cotranslationally, whereas STT3B isoforms can glycosylate sites that were skipped by STT3A complexes. Posttranslational glycosylation by STT3B OST of sequons located close to the carboxyl terminus was observed as long as the protein had not been folded. Competition between protein folding and $N$-glycosylation may hence be a reason for the reduced glycosylation frequency observed for carboxy-terminal sequons (Gavel and von Heijne 1990; Ben-Dor et al. 2004). The presence of two OST isoforms with distinct properties and activities therefore increases the chance of glycosylation for sites that failed to be cotranslationally glycosylated (Ruiz-Canada et al. 2009). Because N-glycosylation is essential for protein folding as well as quality control of this process, higher levels of glycosylation increase the chance of successful protein folding. Therefore the increasing complexity of the $N$-glycosylation process in the ER observed in eukaryotes might correlate with the selective pressure to accommodate as many $N$-glycosylation sites as possible (Schwarz and Aebi 2011).

\section{Functions of OST Subunits}

Because the OSTs of $S$. cerevisiae, plants, and mammals are multisubunit complexes, much research has sought to elucidate the functions of individual complex subunits. Mutagenesis studies have identified conditional mutants of several essential OST subunits. Such mutations result in hypoglycosylation phenotypes, but no specific function could be assigned to the OST subunits (te Heesen et al. 1992; Silberstein et al. 1995; Spirig et al. 1997). It was suspected, though, that noncatalytic subunits may regulate LLO substrate specificity and may serve as "adaptors" that promote interactions with the highly diverse spectrum of polypeptide substrates.

Different biochemical studies with yeast and mammalian OSTs and the identification of a bacterial OST, consisting of only one protein, finally led to the conclusion that STT3 encodes the catalytically active OST subunit (Wacker et al. 2002; Yan and Lennarz 2002; Kelleher et al. 2003; Nilsson et al. 2003). Several homologs of STT3 were identified in kinetoplastids. They function as single subunit OSTs, adding further evidence that STT3 indeed is the catalytic subunit of complex OST (Castro et al. 2006; Parsaie Nasab et al. 2008; Hese et al. 2009; Izquierdo et al. 2009).

The recently solved crystal structure of a bacterial STT3 homolog led to a mechanistic proposal for the glycosylation reaction. Importantly, the most highly conserved WWDxG motif in this protein family interacts with the threonine/ serine of the NxT/S sequon but does not seem to take part in the catalytic reaction as previously suggested (Igura et al. 2008; Lizak et al. 2011), and the crystal structure of PglB excludes specific conformations of the peptide substrate to activate the side-chain amide of the acceptor asparagine (Bause and Legler 1981; Imperiali et al. 1992). Instead, a "twisted amide" intermediate was proposed (Lizak et al. 2011).

Much less is known about LLO substrate recognition by OST. Kinetic models that are based on in vitro studies predict that substrate selection for fully glucosylated LLOs is accomplished by the OST complex via an allosteric regulation involving a regulatory and a catalytic binding site for the LLO substrate (Pathak et al. 1995; Karaoglu et al. 2001; Kelleher et al. 2007). Studies performed with mammalian OSTs led to insights into possible functions of other complex subunits. Ribophorin I may be involved in targeting the ribosome to the ER membrane (Yu et al. 1990). In addition, ribophorin I interacts with a subset of polypeptide substrates and presents them to the catalytic subunit STT3 to facilitate efficient glycosylation of these proteins (Wilson and High 2007; Wilson et al. 2008). Knockdown of OST48 and DAD1 by small interfering RNA ( siRNA) results in destabilization of both OST complex isoforms (Roboti and High 2012b). KCP2 associates mainly, or even exclusively, with STT3A complex isoforms, and knockdown experiments led to the conclusion that KCP2 may facilitate the glycosylation of selected substrate proteins (Roboti and High 2012a,b). DC2 might interact with the $\gamma$-secretase and seems not to be directly involved in $\mathrm{N}$ glycosylation (Wilson et al. 2011). 
Ost3p and Ost6p define in S. cerevisiae two OST complex isoforms (Schwarz et al. 2005). Analysis of glycosylation efficiency for numerous glycosylation sites of different proteins revealed that Ost3p and Ost6p OST isoforms facilitate efficient glycosylation of distinct glycosylation sites. Several sites were only efficiently glycosylated in the presence of either the Ost3p or the Ost6p OST complex (Schulz and Aebi 2009). Structural and biochemical characterization revealed an oxidoreductase activity of these subunits and led to a model proposing that they prevent certain substrate polypeptides from oxidatively folding by forming mixed disulphides with the polypeptide substrate (Schulz et al. 2009). Indeed, the formation of disulphide bonds was found to interfere with glycosylation when the glycosylation site is located close to a cysteine residue (Allen et al. 1995). In addition, OST isoforms were suggested to be associated with components of the translocon (i.e., OST3 with SEC61 and OST6 with SSH1), resulting in specific translocon/OST complexes (Yan and Lennarz 2005). Whether this has an influence on glycosylation of distinct subsets of substrate proteins has not been addressed so far.

\section{CONCLUDING REMARKS}

$N$-linked glycosylation plays an essential role in the folding and the quality control of proteins in the ER. Therefore, a tightly controlled and conserved biosynthetic pathway ensures the correct assembly of the glycan, and the specificity of the OST guarantees that only mature oligosaccharides are transferred to substrate polypeptides (Burda et al. 1999; Helenius and Aebi 2004). Numerous diseases associated with defects in the $N$-glycosylation pathway underline its importance in humans (Haeuptle and Hennet 2009; Hennet 2012).

Although prokaryotic $N$-glycosylation systems show remarkable similarity to eukaryotic $N$-glycosylation in the ER, the glycans transferred to proteins are quite diverse (Schwarz and Aebi 2011). Glycosylation of proteins in prokaryotes occurs after folding. This glycosylation of folded proteins restricts the range of possible substrates to surface-exposed sites accessible to the OST (Kowarik et al. 2006; Dell et al. 2010), whereas attachment of glycans to proteins before folding in eukaryotes allows a wide range of polypeptides to be glycosylated and to use the $N$-glycans as a signal that displays the folding state of a protein.

\section{REFERENCES}

Abu-Qarn M, Eichler J. 2007. An analysis of amino acid sequences surrounding archaeal glycoprotein sequons. Archaea 2: 73-81.

Adair WL Jr, Cafmeyer N. 1987. Characterization of the Saccharomyces cerevisiae cis-prenyltransferase required for dolichyl phosphate biosynthesis. Arch Biochem Biophys 259: 589-596.

Aebi M, Gassenhuber J, Domdey H, te Heesen S. 1996. Cloning and characterization of the ALG3 gene of Saccharomyces cerevisiae. Glycobiology 6: 439-444.

Aebi M, Bernasconi R, Clerc S, Molinari M. 2010. N-glycan structures: Recognition and processing in the ER. Trends Biochem Sci 35: 74-82.

Allen S, Naim HY, Bulleid NJ. 1995. Intracellular folding of tissue-type plasminogen activator. Effects of disulfide bond formation on $N$-linked glycosylation and secretion. J Biol Chem 270: 4797-4804.

Bano-Polo M, Baldin F, Tamborero S, Marti-Renom MA, Mingarro I. 2011. N-Glycosylation efficiency is determined by the distance to the C-terminus and the amino acid preceding an Asn-Ser-Thr sequon. Protein Sci 20: 179-186.

Bause E. 1983. Structural requirements of $N$-glycosylation of proteins. Studies with proline peptides as conformational probes. Biochem J 209: 331-336.

Bause E, Legler G. 1981. The role of the hydroxy amino acid in the triplet sequence Asn-Xaa-Thr(Ser) for the N-glycosylation step during glycoprotein biosynthesis. Biochem J 195: 639-644.

Ben-Dor S, Esterman N, Rubin E, Sharon N. 2004. Biases and complex patterns in the residues flanking protein $N$ glycosylation sites. Glycobiology 14: 95-101.

Bickel T, Lehle L, Schwarz M, Aebi M, Jakob CA. 2005. Biosynthesis of lipid-linked oligosaccharides in Saccharomyces cerevisiae: $\mathrm{Alg} 13 \mathrm{p}$ and $\mathrm{Alg} 14 \mathrm{p}$ form a complex required for the formation of $\mathrm{GlcNAc}(2)$-PP-dolichol. J Biol Chem 280: 34500-34506.

Boles E, Liebetrau W, Hofmann M, Zimmermann FK. 1994. A family of hexosephosphate mutases in Saccharomyces cerevisiae. Eur J Biochem 220: 83-96.

Breuer W, Klein RA, Hardt B, Bartoschek A, Bause E. 2001. Oligosaccharyltransferase is highly specific for the hydroxy amino acid in Asn-Xaa-Thr/Ser. FEBS Lett 501: 106-110.

Burda P, Aebi M. 1998. The ALG10 locus of Saccharomyces cerevisiae encodes the $\alpha-1,2$ glucosyltransferase of the endoplasmic reticulum: The terminal glucose of the lipid-linked oligosaccharide is required for efficient $N$ linked glycosylation. Glycobiology 8: 455-462. 
Burda P, Aebi M. 1999. The dolichol pathway of $N$-linked glycosylation. Biochim Biophys Acta 1426: 239-257.

Burda P, Jakob CA, Beinhauer J, Hegemann JH, Aebi M. 1999. Ordered assembly of the asymmetrically branched lipid-linked oligosaccharide in the endoplasmic reticulum is ensured by the substrate specificity of the individual glycosyltransferases. Glycobiology 9: 617-625.

Cantagrel V, Lefeber DJ, Ng BG, Guan Z, Silhavy JL, Bielas SL, Lehle L, Hombauer H, Adamowicz M, Swiezewska E, et al. 2010. SRD5A3 is required for converting polyprenol to dolichol and is mutated in a congenital glycosylation disorder. Cell 142: 203-217.

Castro O, Movsichoff F, Parodi AJ. 2006. Preferential transfer of the complete glycan is determined by the oligosaccharyltransferase complex and not by the catalytic subunit. Proc Natl Acad Sci 103: 14756-14760.

Chavan M, Yan A, Lennarz WJ. 2005. Subunits of the translocon interact with components of the oligosaccharyl transferase complex. J Biol Chem 280: 22917-22924.

Chen W, Helenius J, Braakman I, Helenius A. 1995. Cotranslational folding and calnexin binding during glycoprotein synthesis. Proc Natl Acad Sci 92: 6229-6233.

Chen AP, Chang SY, Lin YC, Sun YS, Chen CT, Wang AH, Liang PH. 2005. Substrate and product specificities of cistype undecaprenyl pyrophosphate synthase. Biochem J 386: $169-176$.

Cipollo JF, Trimble RB. 2000. The accumulation of Man(6)GlcNAc(2)-PP-dolichol in the Saccharomyces cerevisiae $\Delta$ alg9 mutant reveals a regulatory role for the Alg3p $\alpha 1,3$-Man middle-arm addition in downstream oligosaccharide-lipid and glycoprotein glycan processing. J Biol Chem 275: 4267-4277.

Cipollo JF, Trimble RB. 2002. The Saccharomyces cerevisiae alg $12 \Delta$ mutant reveals a role for the middle-arm $\alpha 1,2$ Man- and upper-arm $\alpha 1,2 \mathrm{Man} \alpha 1,6 \mathrm{Man}$-residues of Glc3Man9GlcNAc2-PP-Dol in regulating glycoprotein glycan processing in the endoplasmic reticulum and Golgi apparatus. Glycobiology 12: 749-762.

Cipollo JF, Trimble RB, Chi JH, Yan Q, Dean N. 2001. The yeast ALG11 gene specifies addition of the terminal $\alpha 1,2$ Man to the Man5GlcNAc2-PP-dolichol N-glycosylation intermediate formed on the cytosolic side of the endoplasmic reticulum. J Biol Chem 276: 21828-21840.

Couto JR, Huffaker TC, Robbins PW. 1984. Cloning and expression in Escherichia coli of a yeast mannosyltransferase from the asparagine-linked glycosylation pathway. J Biol Chem 259: 378-382.

Culyba EK, Price JL, Hanson SR, Dhar A, Wong CH, Gruebele M, Powers ET, Kelly JW. 2011. Protein nativestate stabilization by placing aromatic side chains in $\mathrm{N}$ glycosylated reverse turns. Science 331: 571-575.

Daran JM, Dallies N, Thines-Sempoux D, Paquet V, Francois J. 1995. Genetic and biochemical characterization of the UGP1 gene encoding the UDP-glucose pyrophosphorylase from Saccharomyces cerevisiae. Eur J Biochem 233: $520-530$.

Dell A, Galadari A, Sastre F, Hitchen P. 2010. Similarities and differences in the glycosylation mechanisms in prokaryotes and eukaryotes. Int J Microbiol 2010: 148178.

Dickinson JR. 1991. Biochemical and genetic studies on the function of, and relationship between, the PGI1- and
CDC30-encoded phosphoglucose isomerases in Saccharomyces cerevisiae. J Gen Microbiol 137: 765-770.

Doucey MA, Hess D, Cacan R, Hofsteenge J. 1998. Protein $\mathrm{C}$-mannosylation is enzyme-catalysed and uses dolichylphosphate-mannose as a precursor. Mol Biol Cell 9: 291-300.

Elbein AD. 1984. Inhibitors of the biosynthesis and processing of $\mathrm{N}$-linked oligosaccharides. CRC Crit Rev Biochem 16: $21-49$.

Fang X, Gibbs BS, Coward JK. 1995. Synthesis and evaluation of synthetic analogues of dolichyl-P-P-chitobiose as oligosaccharyltransferase substrates. Bioorgan Med Chem Lett 5: 2701-2706.

Fernandez F, Rush JS, Toke DA, Han GS, Quinn JE, Carman GM, Choi JY, Voelker DR, Aebi M, Waechter CJ. 2001. The CWH8 gene encodes a dolichyl pyrophosphate phosphatase with a luminally oriented active site in the endoplasmic reticulum of Saccharomyces cerevisiae. J Biol Chem 276: 41455-41464.

Fernandez F, Shridas P, Jiang S, Aebi M, Waechter CJ. 2002. Expression and characterization of a human cDNA that complements the temperature-sensitive defect in dolichol kinase activity in the yeast sec59-1 mutant: The enzymatic phosphorylation of dolichol and diacylglycerol are catalyzed by separate CTP-mediated kinase activities in Saccharomyces cerevisiae. Glycobiology 12: 555-562.

Frank CG, Aebi M. 2005. ALG9 mannosyltransferase is involved in two different steps of lipid-linked oligosaccharide biosynthesis. Glycobiology 15: 1156-1163.

Frank CG, Sanyal S, Rush JS, Waechter CJ, Menon AK. 2008. Does Rft1 flip an $\mathrm{N}$-glycan lipid precursor? Nature 454: E3-E4; discussion E4-E5.

Gao XD, Nishikawa A, Dean N. 2004. Physical interactions between the Alg1, Alg2, and Alg11 mannosyltransferases of the endoplasmic reticulum. Glycobiology 14: 559-570.

Gavel Y, von Heijne G. 1990. Sequence differences between glycosylated and non-glycosylated Asn-X-Thr/Ser acceptor sites: Implications for protein engineering. Protein Eng 3: 433-442.

Grabinska KA, Cui J, Chatterjee A, Guan Z, Raetz CR, Robbins PW, Samuelson J. 2010. Molecular characterization of the cis-prenyltransferase of Giardia lamblia. Glycobiology 20: 824-832.

Haeuptle MA, Hennet T. 2009. Congenital disorders of glycosylation: An update on defects affecting the biosynthesis of dolichol-linked oligosaccharides. Hum Mutat 30: $1628-1641$.

Hanson SR, Culyba EK, Hsu TL, Wong CH, Kelly JW, Powers ET. 2009. The core trisaccharide of an $\mathrm{N}$-linked glycoprotein intrinsically accelerates folding and enhances stability. Proc Natl Acad Sci 106: 3131-3136.

Harada Y, Li H, Lennarz WJ. 2009. Oligosaccharyltransferase directly binds to ribosome at a location near the translocon-binding site. Proc Natl Acad Sci 106: 6945-6949.

Hashimoto H, Sakakibara A, Yamasaki M, Yoda K. 1997. Saccharomyces cerevisiae VIG9 encodes GDP-mannose pyrophosphorylase, which is essential for protein glycosylation. J Biol Chem 272: 16308-16314.

Helenius A, Aebi M. 2004. Roles of N-linked glycans in the endoplasmic reticulum. Annu Rev Biochem 73: 10191049. 
Helenius J, Ng DT, Marolda CL, Walter P, Valvano MA, Aebi M. 2002. Translocation of lipid-linked oligosaccharides across the ER membrane requires $\mathrm{Rft} 1$ protein. Nature 415: 447-450.

Heller L, Orlean P, Adair WL Jr. 1992. Saccharomyces cerevisiae sec59 cells are deficient in dolichol kinase activity. Proc Natl Acad Sci 89: 7013-7016.

Hennet T. 2012. Diseases of glycosylation beyond classical congenital disorders of glycosylation. Biochim Biophys Acta 1820: 1306-1317.

Hese K, Otto C, Routier FH, Lehle L. 2009. The yeast oligosaccharyltransferase complex can be replaced by STT3 from Leishmania major. Glycobiology 19: 160-171.

Igura M, Maita N, Kamishikiryo J, Yamada M, Obita T, Maenaka K, Kohda D. 2008. Structure-guided identification of a new catalytic motif of oligosaccharyltransferase. EMBO J 27: 234-243.

Imperiali B, Shannon KL, Rickert KW. 1992. Role of peptide conformation in asparagine-linked glycosylation. J Am Chem Soc 114: 7942-7944.

Izquierdo L, Schulz BL, Rodrigues JA, Guther ML, Procter JB, Barton GJ, Aebi M, Ferguson MA. 2009. Distinct donor and acceptor specificities of Trypanosoma brucei oligosaccharyltransferases. EMBO J 28: 2650-2661.

Jung P, Tanner W. 1973. Identification of the lipid intermediate in yeast mannan biosynthesis. Eur J Biochem 37: $1-6$.

Kaji H, Saito H, Yamauchi Y, Shinkawa T, Taoka M, Hirabayashi J, Kasai K, Takahashi N, Isobe T. 2003. Lectin affinity capture, isotope-coded tagging and mass spectrometry to identify $\mathrm{N}$-linked glycoproteins. Nat Biotechnol 21: 667-672.

Kampf M, Absmanner B, Schwarz M, Lehle L. 2009. Biochemical characterization and membrane topology of Alg2 from Saccharomyces cerevisiae as a bifunctional $\alpha 1,3-$ and 1,6-mannosyltransferase involved in lipidlinked oligosaccharide biosynthesis. J Biol Chem 284: 11900-11912.

Karamyshev AL, Kelleher DJ, Gilmore R, Johnson AE, von Heijne G, Nilsson I. 2005. Mapping the interaction of the STT3 subunit of the oligosaccharyl transferase complex with nascent polypeptide chains. J Biol Chem 280: 40489-40493.

Karaoglu D, Kelleher DJ, Gilmore R. 2001. Allosteric regulation provides a molecular mechanism for preferential utilization of the fully assembled dolichol-linked oligosaccharide by the yeast oligosaccharyltransferase. Biochemistry 40: 12193-12206.

Kasturi L, Chen H, Shakin-Eshleman SH. 1997. Regulation of $\mathrm{N}$-linked core glycosylation: Use of a site-directed mutagenesis approach to identify Asn-Xaa-Ser/Thr sequons that are poor oligosaccharide acceptors. Biochem J 323: 415-419.

Kelleher DJ, Gilmore R. 2006. An evolving view of the eukaryotic oligosaccharyltransferase. Glycobiology 16: 47R$62 \mathrm{R}$.

Kelleher DJ, Karaoglu D, Mandon EC, Gilmore R. 2003. Oligosaccharyltransferase isoforms that contain different catalytic STT3 subunits have distinct enzymatic properties. Mol Cell 12: 101-111.
Kelleher DJ, Banerjee S, Cura AJ, Samuelson J, Gilmore R. 2007. Dolichol-linked oligosaccharide selection by the oligosaccharyltransferase in protist and fungal organisms. J Cell Biol 177: 29-37.

Kepes F, Schekman R. 1988. The yeast SEC53 gene encodes phosphomannomutase. J Biol Chem 263: 9155-9161.

Kharel Y, Takahashi S, Yamashita S, Koyama T. 2006. Manipulation of prenyl chain length determination mechanism of cis-prenyltransferases. FEBS J 273: 647-657.

Kowarik M, Kung S, Martoglio B, Helenius A. 2002. Protein folding during cotranslational translocation in the endoplasmic reticulum. Mol Cell 10: 769-778.

Kowarik M, Numao S, Feldman MF, Schulz BL, Callewaert N, Kiermaier E, Catrein I, Aebi M. 2006. N-linked glycosylation of folded proteins by the bacterial oligosaccharyltransferase. Science 314: 1148-1150.

Kukuruzinska MA, Robbins PW. 1987. Protein glycosylation in yeast: Transcript heterogeneity of the ALG7 gene. Proc Natl Acad Sci 84: 2145-2149.

Lairson LL, Henrissat B, Davies GJ, Withers SG. 2008. Glycosyltransferases: Structures, functions, and mechanisms. Annu Rev Biochem 77: 521-555.

Lizak C, Gerber S, Numao S, Aebi M, Locher KP. 2011. X-ray structure of a bacterial oligosaccharyltransferase. Nature 474: 350-355.

Low P, Dallner G, Mayor S, Cohen S, Chait BT, Menon AK. 1991. The mevalonate pathway in the bloodstream form of Trypanosoma brucei. Identification of dolichols containing 11 and 12 isoprene residues. J Biol Chem 266: 19250-19257.

Lu J, Takahashi T, Ohoka A, Nakajima K, Hashimoto R, Miura N, Tachikawa H, Gao XD. 2012. Alg14 organizes the formation of a multiglycosyltransferase complex involved in initiation of lipid-linked oligosaccharide biosynthesis. Glycobiology 22: 504-516.

Maeda Y, Tomita S, Watanabe R, Ohishi K, Kinoshita T. 1998. DPM2 regulates biosynthesis of dolichol phosphate-mannose in mammalian cells: Correct subcellular localization and stabilization of DPM1, and binding of dolichol phosphate. EMBO J 17: 4920-4929.

Maeda Y, Tanaka S, Hino J, Kangawa K, Kinoshita T. 2000. Human dolichol-phosphate-mannose synthase consists of three subunits, DPM1, DPM2 and DPM3. EMBO J 19: $2475-2482$.

Marshall RD. 1972. Glycoproteins. Annu Rev Biochem 41: 673-702.

Matsui T, Takita E, Sato T, Kinjo S, Aizawa M, Sugiura Y, Hamabata T, Sawada K, Kato K. 2011. N-glycosylation at noncanonical Asn-X-Cys sequences in plant cells. Glycobiology 21: 994-999.

McCloskey MA, Troy FA. 1980. Paramagnetic isoprenoid carrier lipids. 2. Dispersion and dynamics in lipid membranes. Biochemistry 19: 2061-2066.

Miletich JP, Broze GJ Jr. 1990. $\beta$ protein C is not glycosylated at asparagine 329 . The rate of translation may influence the frequency of usage at asparagine-X-cysteine sites. $J$ Biol Chem 265: 11397-11404.

Milewski S, Gabriel I, Olchowy J. 2006. Enzymes of UDPGlcNAc biosynthesis in yeast. Yeast 23: 1-14. 
Mohorko E, Glockshuber R, Aebi M. 2011. Oligosaccharyltransferase: The central enzyme of $N$-linked protein glycosylation. J Inherit Metab Dis 34: 869-878.

Nilsson IM, von Heijne G. 1993. Determination of the distance between the oligosaccharyltransferase active site and the endoplasmic reticulum membrane. J Biol Chem 268: $5798-5801$.

Nilsson I, von Heijne G. 2000. Glycosylation efficiency of Asn-Xaa-Thr sequons depends both on the distance from the $\mathrm{C}$ terminus and on the presence of a downstream transmembrane segment. J Biol Chem 275: $17338-$ 17343.

Nilsson I, Kelleher DJ, Miao Y, Shao Y, Kreibich G, Gilmore R, von Heijne G, Johnson AE. 2003. Photocross-linking of nascent chains to the STT3 subunit of the oligosaccharyltransferase complex. J Cell Biol 161: 715-725.

Noffz C, Keppler-Ross S, Dean N. 2009. Hetero-oligomeric interactions between early glycosyltransferases of the dolichol cycle. Glycobiology 19: 472-478.

O’Reilly MK, Zhang G, Imperiali B. 2006. In vitro evidence for the dual function of Alg2 and Alg11: Essential mannosyltransferases in $\mathrm{N}$-linked glycoprotein biosynthesis. Biochemistry 45: 9593-9603.

Orlean P. 1990. Dolichol phosphate mannose synthase is required in vivo for glycosyl phosphatidylinositol membrane anchoring, $O$ mannosylation, and $N$ glycosylation of protein in Saccharomyces cerevisiae. Mol Cell Biol 10: 5796-5805.

Orlean P, Albright C, Robbins PW. 1988. Cloning and sequencing of the yeast gene for dolichol phosphate mannose synthase, an essential protein. J Biol Chem 263: 17499-17507.

Parsaie Nasab F, Schulz BL, Gamarro F, Parodi AJ, Aebi M. 2008. All in one: Leishmania major STT3 proteins substitute for the whole oligosaccharyltransferase complex in Saccharomyces cerevisiae. Mol Biol Cell 19: 3758-3768.

Pathak R, Hendrickson TL, Imperiali B. 1995. Sulfhydryl modification of the yeast Wbplp inhibits oligosaccharyl transferase activity. Biochemistry 34: 4179-4185.

Petrescu AJ, Milac AL, Petrescu SM, Dwek RA, Wormald MR. 2004. Statistical analysis of the protein environment of $\mathrm{N}$-glycosylation sites: Implications for occupancy, structure, and folding. Glycobiology 14: 103-114.

Reddy VA, Johnson RS, Biemann K, Williams RS, Ziegler FD, Trimble RB, Maley F. 1988. Characterization of the glycosylation sites in yeast external invertase. I. $\mathrm{N}$-linked oligosaccharide content of the individual sequons. J Biol Chem 263: 6978-6985.

Reddy A, Gibbs BS, Liu YL, Coward JK, Changchien LM, Maley F. 1999. Glycosylation of the overlapping sequons in yeast external invertase: Effect of amino acid variation on site selectivity in vivo and in vitro. Glycobiology 9: 547-555.

Reiss G, te Heesen S, Zimmerman J, Robbins PW, Aebi M. 1996. Isolation of the ALG6 locus of Saccharomyces cerevisiae required for glucosylation in the $\mathrm{N}$-linked glycosylation pathway. Glycobiology 6: 493-498.

Rine J, Hansen W, Hardeman E, Davis RW. 1983. Targeted selection of recombinant clones through gene dosage effects. Proc Natl Acad Sci 80: 6750-6754.
Rip JW, Rupar CA, Ravi K, Carroll KK. 1985. Distribution, metabolism and function of dolichol and polyprenols. Prog Lipid Res 24: 269-309.

Roboti P, High S. 2012a. Keratinocyte-associated protein 2 is a bona fide subunit of the mammalian oligosaccharyltransferase. J Cell Sci 125: 220-232.

Roboti P, High S. 2012b. The oligosaccharyltransferase subunits OST48, DAD1 and KCP2 function as ubiquitous and selective modulators of mammalian $\mathrm{N}$-glycosylation. J Cell Sci 125 (Pt 14): 3474-3484.

Ruiz-Canada C, Kelleher DJ, Gilmore R. 2009. Cotranslational and posttranslational $\mathrm{N}$-glycosylation of polypeptides by distinct mammalian OST isoforms. Cell 136: 272-283.

Rush JS, Waechter CJ. 1995. Transmembrane movement of a water-soluble analogue of mannosylphosphoryldolichol is mediated by an endoplasmic reticulum protein. J Cell Biol 130: 529-536.

Rush JS, Waechter CJ. 2004. Functional reconstitution into proteoliposomes and partial purification of a rat liver ER transport system for a water-soluble analogue of mannosylphosphoryldolichol. Biochemistry 43: $7643-$ 7652.

Rush JS, van Leyen K, Ouerfelli O, Wolucka B, Waechter CJ. 1998. Transbilayer movement of Glc-P-dolichol and its function as a glucosyl donor: Protein-mediated transport of a water-soluble analog into sealed ER vesicles from pig brain. Glycobiology 8: 1195-1205.

Rush JS, Cho SK, Jiang S, Hofmann SL, Waechter CJ. 2002. Identification and characterization of a cDNA encoding a dolichyl pyrophosphate phosphatase located in the endoplasmic reticulum of mammalian cells. J Biol Chem 277: 45226-45234.

Rush JS, Gao N, Lehrman MA, Waechter CJ. 2008. Recycling of dolichyl monophosphate to the cytoplasmic leaflet of the endoplasmic reticulum after the cleavage of dolichyl pyrophosphate on the lumenal monolayer. J Biol Chem 283: 4087-4093.

Rush JS, Gao N, Lehrman MA, Matveev S, Waechter CJ. 2009. Suppression of $\mathrm{Rft} 1$ expression does not impair the transbilayer movement of Man5GlcNAc2-P-P-dolichol in sealed microsomes from yeast. J Biol Chem 284: 19835-19842.

Sagami H, Kurisaki A, Ogura K. 1993. Formation of dolichol from dehydrodolichol is catalyzed by NADPH-dependent reductase localized in microsomes of rat liver. $J$ Biol Chem 268: 10109-10113.

Samuelson J, Banerjee S, Magnelli P, Cui J, Kelleher DJ, Gilmore R, Robbins PW. 2005. The diversity of dolichol-linked precursors to Asn-linked glycans likely results from secondary loss of sets of glycosyltransferases. Proc Natl Acad Sci 102: 1548-1553.

Sanyal S, Menon AK. 2009. Specific transbilayer translocation of dolichol-linked oligosaccharides by an endoplasmic reticulum flippase. Proc Natl Acad Sci 106: 767-772.

Sanyal S, Menon AK. 2010. Stereoselective transbilayer translocation of mannosyl phosphoryl dolichol by an endoplasmic reticulum flippase. Proc Natl Acad Sci 107: 11289-11294.

Sanyal S, Frank CG, Menon AK. 2008. Distinct flippases translocate glycerophospholipids and oligosaccharide 
diphosphate dolichols across the endoplasmic reticulum. Biochemistry 47: 7937-7946.

Sato C, Kim JH, Abe Y, Saito K, Yokoyama S, Kohda D. 2000. Characterization of the $\mathrm{N}$-oligosaccharides attached to the atypical Asn-X-Cys sequence of recombinant human epidermal growth factor receptor. J Biochem 127: $65-72$.

Schenk B, Fernandez F, Waechter CJ. 2001. The ins(ide) and out(side) of dolichyl phosphate biosynthesis and recycling in the endoplasmic reticulum. Glycobiology 11: 61R-70R.

Schulz BL, Aebi M. 2009. Analysis of glycosylation site occupancy reveals a role for Ost3p and Ost6p in site-specific $N$ glycosylation efficiency. Mol Cell Proteomics 8: 357-364.

Schulz BL, Stirnimann CU, Grimshaw JP, Brozzo MS, Fritsch F, Mohorko E, Capitani G, Glockshuber R, Grutter MG, Aebi M. 2009. Oxidoreductase activity of oligosaccharyltransferase subunits Ost3p and Ost6p defines site-specific glycosylation efficiency. Proc Natl Acad Sci 106: 11061-11066.

Schwarz F, Aebi M. 2011. Mechanisms and principles of Nlinked protein glycosylation. Curr Opin Struct Biol 21 576-582.

Schwarz M, Knauer R, Lehle L. 2005. Yeast oligosaccharyltransferase consists of two functionally distinct sub-complexes, specified by either the Ost3p or Ost6p subunit. FEBS Lett 579: 6564-6568.

Shakin-Eshleman SH, Spitalnik SL, Kasturi L. 1996. The amino acid at the $\mathrm{X}$ position of an Asn-X-Ser sequon is an important determinant of $\mathrm{N}$-linked core-glycosylation efficiency. J Biol Chem 271: 6363-6366.

Sharma CB, Knauer R, Lehle L. 2001. Biosynthesis of lipidlinked oligosaccharides in yeast: The ALG3 gene encodes the Dol-P-Man:Man5GlcNAc2-PP-Dol mannosyltransferase. Biol Chem 382: 321-328.

Shental-Bechor D, Levy Y. 2008. Effect of glycosylation on protein folding: A close look at thermodynamic stabilization. Proc Natl Acad Sci 105: 8256-8261.

Shibatani T, David LL, McCormack AL, Frueh K, Skach WR. 2005. Proteomic analysis of mammalian oligosaccharyltransferase reveals multiple subcomplexes that contain Sec61, TRAP, and two potential new subunits. Biochemistry 44: 5982-5992.

Silberstein S, Collins PG, Kelleher DJ, Rapiejko PJ, Gilmore R. 1995. The $\alpha$ subunit of the Saccharomyces cerevisiae oligosaccharyltransferase complex is essential for vegetative growth of yeast and is homologous to mammalian ribophorin I. J Cell Biol 128: 525-536.

Skropeta D. 2009. The effect of individual $N$-glycans on enzyme activity. Bioorg Med Chem 17: 2645-2653.

Smith DJ, Proudfoot A, Friedli L, Klig LS, Paravicini G, Payton MA. 1992. PMI40, an intron-containing gene required for early steps in yeast mannosylation. Mol Cell Biol 12: 2924-2930.

Snider MD, Rogers OC. 1984. Transmembrane movement of oligosaccharide-lipids during glycoprotein synthesis. Cell 36: 753-761.

Spirig U, Glavas M, Bodmer D, Reiss G, Burda P, Lippuner V, te Heesen S, Aebi M. 1997. The STT3 protein is a component of the yeast oligosaccharyltransferase complex. Mol Gen Genet 256: 628-637.
Spirig U, Bodmer D, Wacker M, Burda P, Aebi M. 2005. The $3.4-\mathrm{kDa}$ Ost 4 protein is required for the assembly of two distinct oligosaccharyltransferase complexes in yeast. Glycobiology 15: 1396-1406.

Stagljar I, te Heesen S, Aebi M. 1994. New phenotype of mutations deficient in glucosylation of the lipid-linked oligosaccharide: Cloning of the ALG8 locus. Proc Natl Acad Sci 91: 5977-5981.

Szkopinska A, Karst F, Palamarczyk G. 1996. Products of S cerevisiae cis-prenyltransferase activity in vitro. Biochimie 78: $111-116$.

Tai VW, Imperiali B. 2001. Substrate specificity of the glycosyl donor for oligosaccharyl transferase. J Org Chem 66: 6217-6228.

te Heesen S, Janetzky B, Lehle L, Aebi M. 1992. The yeast WBP1 is essential for oligosaccharyl transferase activity in vivo and in vitro. EMBO J 11: 2071-2075.

te Heesen S, Lehle L, Weissmann A, Aebi M. 1994. Isolation of the ALG5 locus encoding the UDP-glucose:dolichylphosphate glucosyltransferase from Saccharomyces cerevisiae. Eur J Biochem 224: 71-79.

Titani K, Kumar S, Takio K, Ericsson LH, Wade RD, Ashida K, Walsh KA, Chopek MW, Sadler JE, Fujikawa K. 1986. Amino acid sequence of human von Willebrand factor. Biochemistry 25: 3171-3184.

Trimble RB, Byrd JC, Maley F. 1980. Effect of glucosylation of lipid intermediates on oligosaccharide transfer in solubilized microsomes from Saccharomyces cerevisiae. J Biol Chem 255: 11892-11895.

van Berkel MA, Rieger M, te Heesen S, Ram AF, van den Ende H, Aebi M, Klis FM. 1999. The Saccharomyces cerevisiae CWH8 gene is required for full levels of dolichollinked oligosaccharides in the endoplasmic reticulum and for efficient $N$-glycosylation. Glycobiology 9: $243-$ 253.

Vance BA, Wu W, Ribaudo RK, Segal DM, Kearse KP. 1997. Multiple dimeric forms of human CD69 result from differential addition of $\mathrm{N}$-glycans to typical (Asn-X-Ser/ Thr) and atypical (Asn-X-cys) glycosylation motifs. $J$ Biol Chem 272: 23117-23122.

Verostek MF, Atkinson PH, Trimble RB. 1993. Glycoprotein biosynthesis in the alg3 Saccharomyces cerevisiae mutant I. Role of glucose in the initial glycosylation of invertase in the endoplasmic reticulum. J Biol Chem 268: 12095 12103.

Wacker M, Linton D, Hitchen PG, Nita-Lazar M, Haslam SM, North SJ, Panico M, Morris HR, Dell A Wren BW, et al. 2002. N-linked glycosylation in Campylobacter jejuni and its functional transfer into E. coli. Science 298: $1790-1793$.

Walmsley AR, Hooper NM. 2003a. Distance of sequons to the C-terminus influences the cellular $\mathrm{N}$-glycosylation of the prion protein. Biochem J 370: 351-355.

Walmsley AR, Hooper NM. 2003b. Glycosylation efficiency of Asn-Xaa-Thr sequons is independent of distance from the C-terminus in membrane dipeptidase. Glycobiology 13: $641-646$.

Whitley P, Nilsson IM, von Heijne G. 1996. A nascent secretory protein may traverse the ribosome/endoplasmic reticulum translocase complex as an extended chain. J Biol Chem 271: 6241-6244. 
Wilson CM, High S. 2007. Ribophorin I acts as a substratespecific facilitator of $N$-glycosylation. J Cell Sci 120: 648-657.

Wilson CM, Roebuck Q, High S. 2008. Ribophorin I regulates substrate delivery to the oligosaccharyltransferase core. Proc Natl Acad Sci 105: 9534-9539.

Wilson CM, Magnaudeix A, Yardin C, Terro F. 2011. DC2 and keratinocyte-associated protein 2 (KCP2), subunits of the oligosaccharyltransferase complex, are regulators of the $\gamma$-secretase-directed processing of amyloid precursor protein (APP). J Biol Chem 286: 31080-31091.

Yan Q, Lennarz WJ. 2002. Studies on the function of oligosaccharyl transferase subunits. Stt3p is directly involved in the glycosylation process. J Biol Chem 277: $47692-$ 47700.

Yan A, Lennarz WJ. 2005. Two oligosaccharyl transferase complexes exist in yeast and associate with two different translocons. Glycobiology 15: 1407-1415.

Yu YH, Sabatini DD, Kreibich G. 1990. Antiribophorin antibodies inhibit the targeting to the ER membrane of ribosomes containing nascent secretory polypeptides. $J$ Cell Biol 111: 1335-1342.

Zielinska DF, Gnad F, Wisniewski JR, Mann M. 2010. Precision mapping of an in vivo $\mathrm{N}$-glycoproteome reveals rigid topological and sequence constraints. Cell 141: 897-907. 


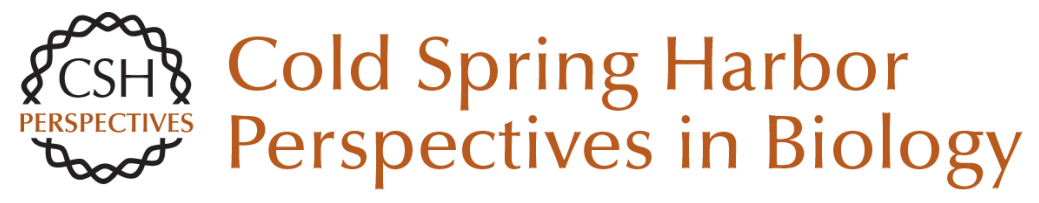

\section{N-Linked Protein Glycosylation in the Endoplasmic Reticulum}

Jörg Breitling and Markus Aebi

Cold Spring Harb Perspect Biol 2013; doi: 10.1101/cshperspect.a013359 originally published online June 10, 2013

\section{Subject Collection The Endoplasmic Reticulum}

Sorting and Export of Proteins at the Endoplasmic Reticulum Ishier Raote, Sonashree Saxena and Vivek Malhotra

Endoplasmic Reticulum Membrane Contact Sites, Lipid Transport, and Neurodegeneration Andrés Guillén-Samander and Pietro De Camilli

AMPylation and Endoplasmic Reticulum Protein Folding Homeostasis Luke A. Perera and David Ron

The Endoplasmic Reticulum and the Fidelity of Nascent Protein Localization Michael J. McKenna and Sichen Shao

Endoplasmic Reticulum Architecture and Inter-Organelle Communication in Metabolic Health and Disease

Ana Paula Arruda and Günes Parlakgül

Regulation and Functions of the ER-Associated Nrf1 Transcription Factor

Gary Ruvkun and Nicolas Lehrbach

Mechanism of Protein Translocation by the Sec61 Translocon Complex Samuel Itskanov and Eunyong Park
Glycerolipid Synthesis and Lipid Droplet

Formation in the Endoplasmic Reticulum Robert V. Farese, Jr. and Tobias C. Walther

The Biogenesis of Multipass Membrane Proteins Luka Smalinskaite and Ramanujan S. Hegde

A TAle of Two Pathways: Tail-Anchored Protein Insertion at the Endoplasmic Reticulum Alina Guna, Masami Hazu, Giovani Pinton Tomaleri, et al.

Cholesterol Transport to the Endoplasmic

Reticulum John P. Kennelly and Peter Tontonoz

The Role of the Rhomboid Superfamily in ER

Protein Quality Control: From Mechanisms and Functions to Diseases Satarupa Bhaduri, Nicola A. Scott and Sonya E. Neal

ER-Phagy: Quality and Quantity Control of the

Endoplasmic Reticulum by Autophagy Haruka Chino and Noboru Mizushima

Structure and Function of the Nuclear Pore Complex

Stefan Petrovic, George W. Mobbs, Christopher J. Bley, et al.

For additional articles in this collection, see http://cshperspectives.cshlp.org/cgi/collection/

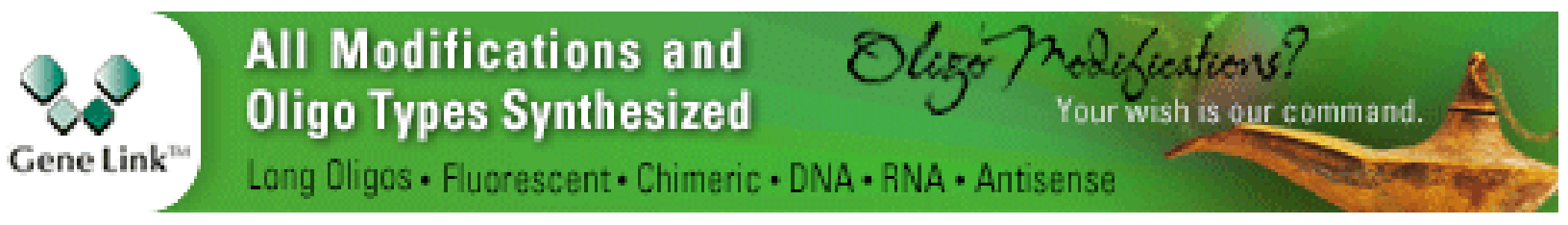




\section{Evolutionary Aspects of the Unfolded Protein Response \\ Kazutoshi Mori}

Post-Translational Regulation of HMG CoA Reductase

Youngah Jo and Russell A. DeBose-Boyd

For additional articles in this collection, see http://cshperspectives.cshlp.org/cgi/collection/

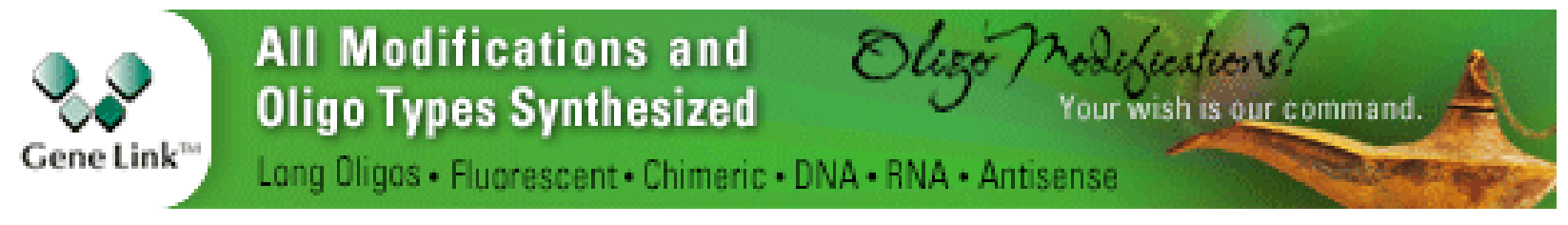

Copyright @ 2013 Cold Spring Harbor Laboratory Press; all rights reserved 